\title{
High Power UV and VUV Excilamps and Their Applications
}

\author{
V. Tarasenko*, S. Avdeev, M. Erofeev, M. Lomaev, E. Sosnin, V. Skakun \\ AND D. SHITZ \\ High Current Electronics Institute, Tomsk, Russia
}

\begin{abstract}
In the present paper, the review of the basic results obtained at the Laboratory of Optical Radiation at High Current Electronics Institute SB RAS during 2007-2009 years is presented. Efficient radiation of $\mathrm{Ar}_{2}, \mathrm{Kr}_{2}, \mathrm{Xe}_{2}$, $\mathrm{KrBr}^{*}, \mathrm{KrCl}^{*}, \mathrm{XeI}^{*}, \mathrm{XeBr}^{*}, \mathrm{XeCl}^{*}, \mathrm{Cl}_{2} *$ molecules and I atoms was obtained in rare gas or in rare gas- $\mathrm{Br}_{2}$ $\left(\mathrm{Cl}_{2}, \mathrm{I}_{2}\right)$ mixtures. Study of radiation parameters and lifetime period of the manufactured barrier discharge excilamps has been performed.
\end{abstract}

PACS numbers: $52.80 . \mathrm{Tn}, 42.72 . \mathrm{Bj}, 32.30 . \mathrm{Jc}$

\section{Introduction}

Excilamps are the sources of incoherent UV and VUV radiation based on the non-equilibrium radiation of exciplex or excimer molecules. Due to the novel industrial applications - cleaning of substrates with VUV radiation, UV curing, UV induced modification of polymer surfaces, UV assisted low-temperature oxidation, UV induced material deposition, water and air purification, different medicine applications excilamps attract much attention during last two decades [1-8]. At present time, excilamps excited by a barrier discharge are the simplest and perspective as well sources of UV and VUV radiation. Much research is devoted to such excilamps.

The industrial applications require the stability of the output radiation spectrum and energetic parameters of excilamps. The aim of present work is to investigate the possibility of excilamps' lifetime and their output power increasing.

\section{Experimental results}

\subsection{Barrier $\mathrm{KrCl}$ excilamp with average radiation power up to $100 \mathrm{~W}$}

Traditionally, sinusoidal oscillators are used as excitation sources. In present work the influence of excitation pulse form on efficiency of a barrier $\mathrm{KrCl}$ excilamps was experimentally studied. The main results of the work performed are the following. The most high specific radiation powers were obtained at excitation of the excilamp by voltage pulses of different polarity at maximum pulsed repetition rate (p.r.r.) of $100 \mathrm{kHz}$, and made, depending on operating surface of excilamp, from 25 up to $60 \mathrm{~mW} / \mathrm{cm}^{2}$.

\footnotetext{
* corresponding author; e-mail: VFT@loi.hcei.tsc.ru
}

From the oscilloscope traces of voltage pulses, current and radiation it is seen that radiation is being registered within the whole current pulse duration.

By using the experience of the influence of excitation parameters a coaxial sealed-off $\mathrm{KrCl}$-excilamp excited by a barrier discharge has been made. Excilamps sizes are as follows: length is $60 \mathrm{~cm}$, external diameter is $65 \mathrm{~mm}$, gas discharge gap space is $10 \mathrm{~mm}$ (Fig. 1). The internal tube of excilamp is water-cooled, and the external tube of the excilamp is air-cooled. In order to have not less than 100 hours lifetime for the excilamp, it was annealed and passivated by chlorine in muffle furnace. A power supply source for the barrier discharge excilamp with average power of up to $1.5 \mathrm{~kW}$ and repetition of bipolar pulses $93 \mathrm{kHz}$ has been designed and made.

Study of radiation parameters and lifetime period of the manufactured excilamp has been performed. Average power of radiation for the just sealed off excilamp exceeded $115 \mathrm{~W}$. Figure 2 shows oscilloscope traces of voltage pulses, current and radiation, as well as calculation voltage curves at gas discharge gap, excilamp barrier capacity, excitation power and energy. Along with operating time, radiation power decreased a bit. Nevertheless, within 100 hours operation, decrease in output radiation power was merely $10 \%$ (Fig. 3). Decrease in radiation power during operation may be diminished using more intensive cooling.

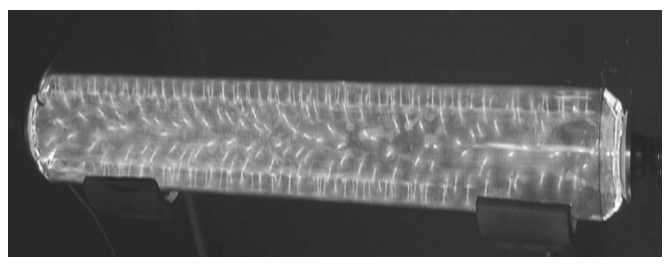

Fig. 1. The appearance of sealed-off KrCl-excilamp excited by a barrier discharge in operation regime. 

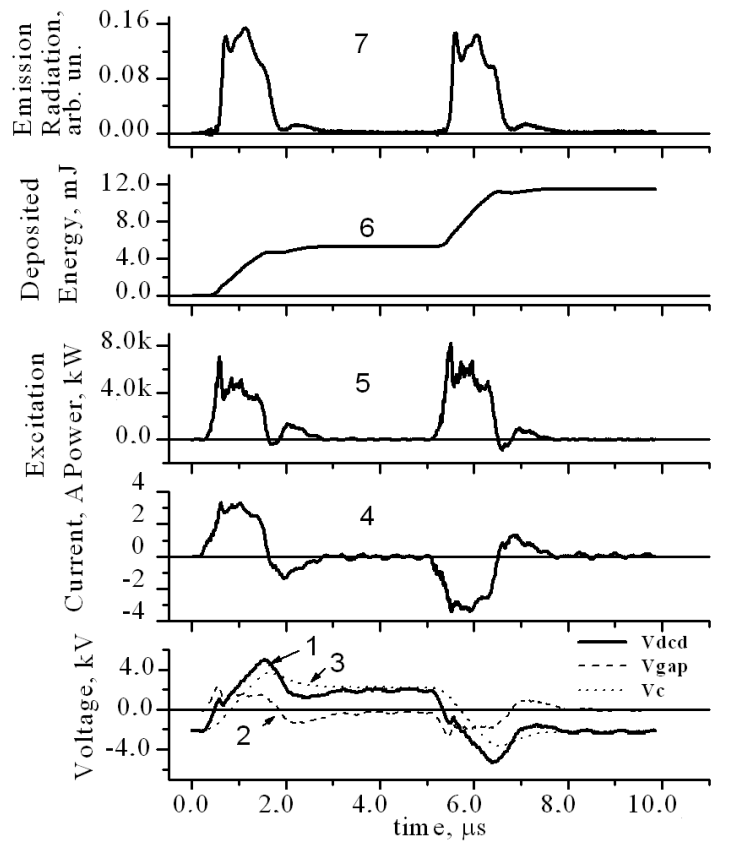

Fig. 2. Oscilloscope traces of excilamp voltage Vdcd (1), calculated curves of gas discharge gap Vgap (2) and excilamps capacity Vc (3) voltages, oscilloscope traces of current pulses (4), calculated curves of excitation power (5) and deposited energy (6), oscilloscope traces of UV radiation intensity (7).

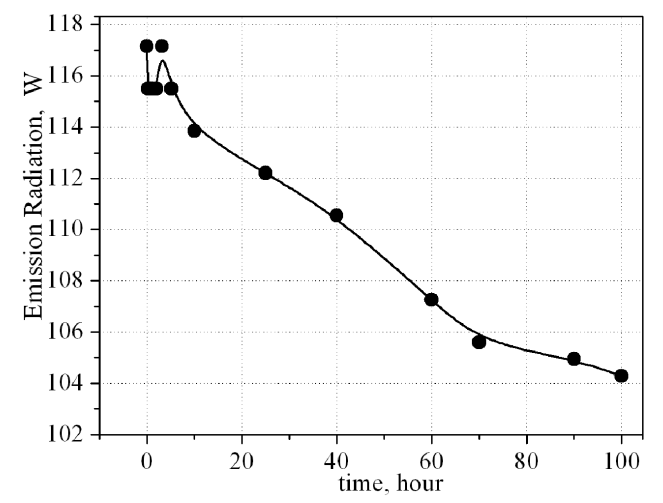

Fig. 3. Output emission radiation versus operation time.

\subsection{Barrier $\mathrm{KrCl}, \mathrm{XeCl}$ and $\mathrm{X} e_{2}^{*}$ excilamps' lifetime testing}

In experiments of lifetime testing $\mathrm{KrCl}$ - and $\mathrm{XeCl}-$ -excilamps listed in Table were used. The photo of XeCl-excilamp in operation regime is presented in Fig. 4. The testing data of the $\mathrm{KrCl}$ - and $\mathrm{XeCl}$-excilamps lifetime are shown in Figs. 5, 6, respectively.
The parameters of KrCl- and XeCl-excilamp.

\begin{tabular}{c|c|c|c}
\hline \hline Working molecule & $\begin{array}{c}\text { Emitter } \\
\text { length }\end{array}$ & $\begin{array}{c}\text { Length of the } \\
\text { discharge area }\end{array}$ & $\begin{array}{c}\text { External wall } \\
\text { temperature }\end{array}$ \\
\hline $\mathrm{KrCl}^{*}(\lambda=222 \mathrm{~nm})$ & $16 \mathrm{~cm}$ & $5 \mathrm{~cm}$ & $\sim 100 \mathrm{~K}$ \\
$\mathrm{XeCl}^{*}(\lambda=308 \mathrm{~nm})$ & $16 \mathrm{~cm}$ & $9 \mathrm{~cm}$ & $\sim 60 \mathrm{~K}$
\end{tabular}

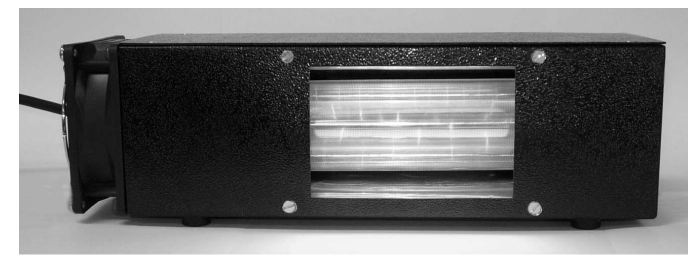

Fig. 4. Photo of XeCl-excilamp in operation regime.

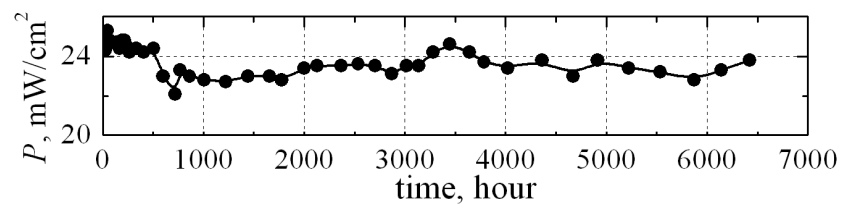

Fig. 5. Dependence of the output power density of the $\mathrm{KrCl}$-excilamp versus time in continuous operation mode.

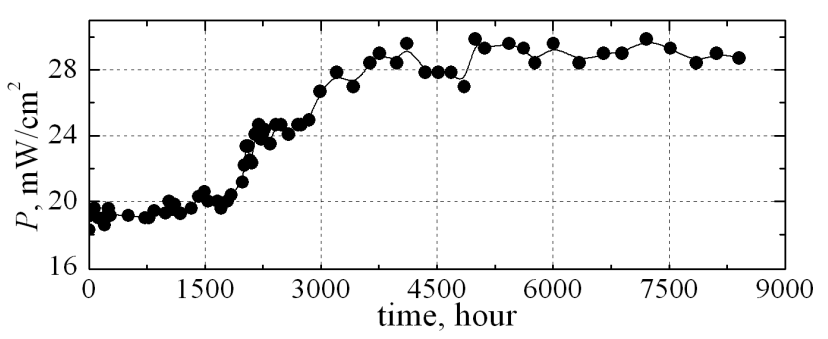

Fig. 6. Dependence of the output power density of the XeCl-excilamp versus time in continuous operation mode.

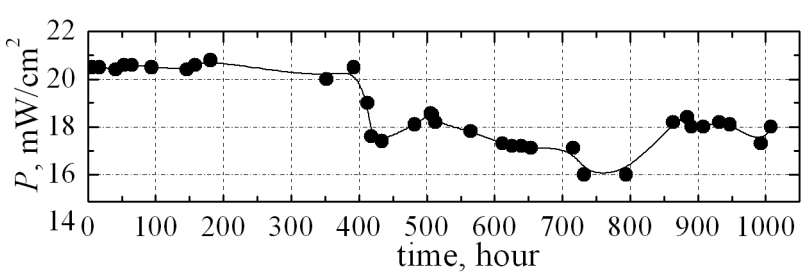

Fig. 7. Dependence of the output power density of the $\mathrm{Xe}_{2}^{*}$-excilamp versus time in continuous operation mode. 
As it is seen in Figs. 5, 6 the value of output power density did not decreased during first 6000-7500 h continuous operation. The output power density reached up to 24 and $27-30 \mathrm{~mW} / \mathrm{cm}^{2}$ for $\mathrm{KrCl}$ - and XeCl-excilamp, respectively. A stable operation was achieved at lower level of excitation power as compared to one corresponding to Figs. 2, 3.

The lifetime of a barrier discharge $\mathrm{Xe}_{2}^{*}$ excilamp's $(\lambda=172 \mathrm{~nm})$ was tested as well. The excilamp was made from two coaxial quartz tubes (KU-2) with the length of $21 \mathrm{~cm}$ and the external and internal diameters of 3.2 and $1 \mathrm{~cm}$, respectively. The test data have shown reduction of the output power of about $11 \%$ for first $450 \mathrm{~h}$ of the uninterrupted operation, while up to $1000 \mathrm{~h}$ this value did not change significantly remaining equal of $16-18 \mathrm{~mW} / \mathrm{cm}^{2}$ (Fig. 7). However, the quartz mechanical strength degraded that leads to the emitter malfunction and replacement.

\section{Conclusion}

Thus, a powerful, up to $100 \mathrm{~W}$ coaxial excilamp excited by a barrier discharge has been created. The lifetimes of $\mathrm{KrCl}^{*}, \mathrm{XeCl}^{*}$ and $\mathrm{Xe}_{2}^{*}$ excilamps were experimentally studied. It was shown that at moderate excitation power level it is possible to achive the lifetime up to $6000-7000 \mathrm{~h}$ and more.

\section{Acknowledgments}

The authors are very thankful to the ISTC (Project \#3583d) for financial supporting and to V. Panarin for technical assistance.

\section{References}

[1] B. Eliasson, U. Kogelschatz, IEEE Trans. Plasma Sci. 19, 309 (1991).

[2] I. Boyd, J. Zhang, Nuclear Instrum. Methods Phys. Res. B 121, 349 (1997).

[3] I. Boyd, J. Zhang, U. Kogelshatz, in: Photo-Excited Processes, Diagnostics and Applications, Ed. A. Peled, Kluwer Academic, The Netherlands 2003, p. 161.

[4] M. Lomaev, V.S. Skakun, E.A. Sosmin, V.F. Tarasenko, D.V. Shitts, M.V. Erofeev, Physics-Usp. 46, 193 (2003).

[5] R. Carman, R. Mildren, J. Phys. D, Appl. Phys. 36, 19 (2003).

[6] U. Kogelschatz, Proc. SPIE 5483, 272 (2004).

[7] M. Lomaev, E.A. Sosmin, V.F. Tarasenko, D.V. Shits, V.S. Skakun, M.V. Erofeev, A.A. Lisenko, Instrum. Exp. Techn. 49, 595 (2006).

[8] K. Becker, and K. Schoenbach, in: Low Temperature Plasma. Fundamentals, Technologies, and Techniques, 2nd ed. Ed. R. Hippler, H. Kersten, M. Schmidt, K.H. Schoenbach, Wiley-VCH Verlag, Weinheim 2, 2008, p. 463. 